\title{
Effect of Insulin Glargine on Cardiovascular Risk Analysed by Mean HRV
}

\section{Marchitto Nicola ${ }^{*}$, Marcinnò Mariaconcetta ${ }^{2}$, Petrucci Alessia ${ }^{2}$, Apicella Giovanni², Dal Maso Serenella Gioia1, Raimondi Gianfranco ${ }^{3}$}

\author{
${ }^{1}$ Internal Medicine Department, Alfredo Fiorini Hospital, Terracina, Italy \\ ${ }^{2}$ Nursing Department, Sapienza University of Rome, Rome, Italy \\ ${ }^{3}$ Department of Medico-Surgical Sciences and Biotechnologies, Sapienza University of Rome, Rome, Italy \\ Email: *n.marchitto@ausl.latina.it
}

How to cite this paper: Nicola, M., Mariaconcetta, M., Alessia, P., Giovanni, A., Gioia, D.M.S. and Gianfranco, R. (2019) Effect of Insulin Glargine on Cardiovascular Risk Analysed by Mean HRV. Health, 11, 20-24.

https://doi.org/10.4236/health.2019.111003

Received: October 17, 2018

Accepted: January 8, 2019

Published: January 11, 2019

Copyright (c) 2019 by author(s) and Scientific Research Publishing Inc. This work is licensed under the Creative Commons Attribution International License (CC BY 4.0).

http://creativecommons.org/licenses/by/4.0/

\begin{abstract}
Type 2 diabetes mellitus is an insidious disease that is increasingly present in geriatric population [1]. The greatest difficulty is represented by glycaemic control in geriatric patients often not very compliant with diet therapy and drug therapy. A new insulin glargine 300 units $/ \mathrm{ml}$ formulation seems improve patient compliance due to the lower volume of insulin to be injected and improved glycaemic control over 24 hours. The HRV signal, derived from digital electrocardiographic recording, is the simplest and most immediate analysis that consists in calculating some temporal parameters [2]. HRV is a simple statistics derived from beat-beat intervals of sinus origin expressed as units of time in milliseconds. Data in the literature indicate that a decrease in HRV, measured with time domain analysis, denotes a worse prognosis and/or an increased risk of mortality in patients with heart disease, especially in the elderly ones.
\end{abstract}

\section{Keywords}

Insulin Glargine, Diabetes, HRV, Cardiovascular Risk, Geriatry

\section{Background}

Type 2 diabetes mellitus is increasingly present geriatric population [1]. Recently, a new 300 units $/ \mathrm{ml}$ insulin glargine formulation has been introduced in clinical practice to improve patient compliance due to lower volume of insulin to be injected and improved glycemic control within 24 hours. The HRV signal, derived from digital electrocardiographic recording, allows us to calculate some temporal parameters [2]. Data in the literature indicate that a decrease in HRV, 
measured by the analysis of the time domain, shows a worse prognosis in particular in the elderly.

\section{Aim}

The aim of our study is to evaluate, through the Heart Rate Variability study, the possible influence of the new insulin glargine formulation 300 units/ml [3] on the neurovegetative tone and on the arrhythmic cardiovascular risk.

\section{Materials and Methods}

In the period between February 2018 and April 2018 we enrolled 30 patients. 5 patients (16.6\%) are not compliant and therefore the real number of enrolled patients is 25 (13 male and 12 female) with an average age of $75 \pm 13$ years with type II diabetes mellitus. All patients gave their informed consent and ethical approval. In the enrolment phase, the patients underwent the evaluation of the glycaemic profile at 20.00 by means of glucostick and the subsequent digital electrocardiographic recording by means of a Medixai electrocardiograph. Elegibility patient have diabetes mellitus treated with insulin glargine. Exclusion criteria are the presence of atrial fibrillation for BIAS in HRV evaluation. At the end of the enrolment, the patients were treated with the new insulin glargine formulation 300 units/ml at the same dosage as the old insulin glargine. After 1 hour from insulin administration, the patients were again subjected to the evaluation of the glycaemic profile by means of glucostick and to the subsequent recording of digital control electrocardiography. The pre and post-treatment glycaemic values were used as a parameter to confirm the action of insulin glargine, administered to patients.

The analysis of the HRV in the time domain was performed using the Kubios software for Windows XP. For this study were used statistical parameters of STD variability or standard deviation of the R-R intervals with respect to the mean; NN50 or number of consecutive intervals with difference $>50 \mathrm{msec}$; pNN50 or percentage of the NN50 intervals compared to the total of the measured intervals (a threshold of $20 \mathrm{msec}$ can demonstrate superior discrimination between physiological and pathological HRV) [4]; RMSSD or square root of the mean squared differences between adjacent R-R intervals; SDNN or calculation of the standard deviation of a series of intervals $\mathrm{NN}, \mathrm{AR} \mathrm{LF} / \mathrm{HF}$ or regression analysis of the LF/HF ratio. Statistical analysis was performed with Paired T-test for small group of the patients using the Sigmastat 3.5 software for windows XP.

\section{Results}

The results of our study have shown that the new formulation of insulin glargine (300 units/ml) [5], even though it has determined a statistically significant reduction in glycaemic values due to insulin glargine activity (Table 1) before the electrocardiographic recording performed as a control, and a statistically significant increase of the Heart Rate index of a reduction in heart rate frequencies 
Table 1. Descriptive statistics: RRvar STD (standard deviation of the R-R intervals compared to the mean); NN50 (number of consecutive intervals with difference $>50 \mathrm{msec}$ ); pNN50 (percentage of the NN50 intervals with respect to the total of the measured intervals, with a threshold of $20 \mathrm{msec}$ ); RMSSD (square root of the average of the squared differences between adjacent R-R intervals); SDNN (calculation of the standard deviation of a series of intervals NN); AR LF/HF (regression analysis of the LF/HF ratio). “»”: statistically significant changes.

\begin{tabular}{cccc}
\hline & Base \pm DS & Control \pm DS & Probability (P) \\
\hline Glucose $(\mathrm{mg} / \mathrm{dl})$ & $242.500 \pm 77.768$ & $190.500 \pm 72.109$ & $\mathrm{P}<0.001^{*}$ \\
RR var (ms) & $811.717 \pm 176.049$ & $839.942 \pm 177.081$ & $\mathrm{P}=0.035^{*}$ \\
NN50 (ms) & $58.542 \pm 66.835$ & $61.833 \pm 69.133$ & $\mathrm{P}=0.691$ \\
PNN50 & $23.242 \pm 26.540$ & $23.600 \pm 26.317$ & $\mathrm{P}=0.892$ \\
RMSSD & $53.600 \pm 46.600$ & $57.508 \pm 54.778$ & $\mathrm{P}=0.577$ \\
SDNN & $43.271 \pm 36.614$ & $43.500 \pm 41.433$ & $\mathrm{P}=0.961$ \\
AR LF/HF & $1.457 \pm 1.965$ & $1.390 \pm 2.208$ & $\mathrm{P}=0.910$ \\
\hline
\end{tabular}

(Table 1), but does not establish any statistically significant changes in neurovegetative tone, that would negatively affect the cardiovascular risk in geriatric patients with multiple co-morbidities.

\section{Discussion}

Insulin glargine is a human insulin analog designed to have a low $\mathrm{pH}$ neutral solubility while the solubility is highest for $\mathrm{pH}$ values equal to 4 . After subcutaneous injection, the acidic insulin solution is neutralized giving rise to the formation of precipitate insulin which gradually releases small amounts of insulin glargine.

The administration of the new insulin glargine formulation (300 units $/ \mathrm{ml}$ ) allows improving the glycaemic profile in 24 hours as reported by the pharmacodynamic studies that have shown how the insulin effect persists up to 36 hours, due to the prolonged release of insulin glargine from the precipitate of this new formulation. This can be attributable to the reduction in injection volume of about $2 / 3$. Such reduction in injection volume leads to a decrease in the area of the precipitate responsible for the release of soluble glargine insulin. The dosage of the new insulin glargine can be optimized by adding $10 \%-20 \%$ of the usual dosage of the old-generation insulin glargine (100 units/ml) since the insulin glargine of the old generation (100 units $/ \mathrm{ml}$ ) and the new formulation of insulin glargine (300 units/ml) are not bioequivalent and are not directly interchangeable. 
According to the data sheet, the dosage of the new generation glargine insulin (300 units $/ \mathrm{ml}$ ) can be calculated with the formula 0.2 units $/ \mathrm{kg}$ of body weight or increasing the dosage of the new generation insulin by $10 \%-20 \%$ (300 units $/ \mathrm{ml}$ ) compared to the old glargine insulin dosage (100 units $/ \mathrm{ml})$. The new insulin glargine formulation ensure a good control of glycaemia [6] and ensure a neutrality in terms of effects on arrhythmic cardiovascular risk, which represent a highly represented problem in the geriatric population affected by co-morbidities such as heart failure, atrial fibrillation and electrolyte disorders, concomitant with chronic renal function abnormalities.

\section{Conclusion}

Preliminary data obtained from our study shown that the new insulin glargine formulation 300 units $/ \mathrm{ml}$ represents a new therapeutic option that allows improving the glycaemic profile (Figure 1), given the best solubility in relation to the minor surface of the precipitate [6] and improve with a statistically significant variation the RR-variability (confirmed by the data deriving from the analysis of the RR variability index) (Figure 2) without altering the neurovegetative structure and therefore the cardiovascular risk (confirmed by the data deriving from the regression analysis of the LF/HF ratio). Our data give comfortable results but further evaluations are needed to have conclusive results.

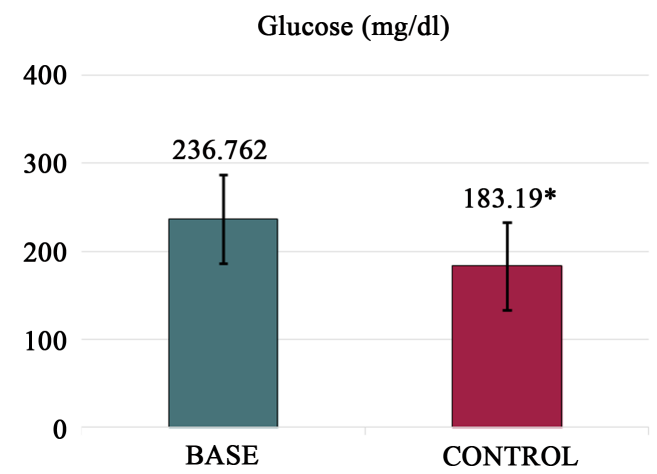

Figure 1. Descriptive statistics about glucose value. “*”: statistically significant changes.

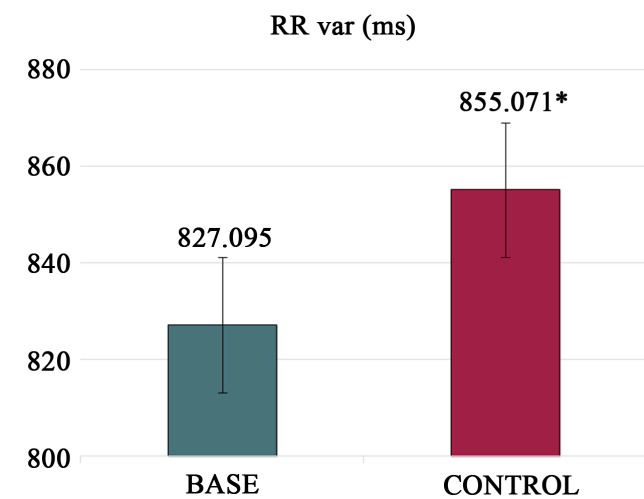

Figure 2. Descriptive statistics about R-R variability index. "“”: statistically significant changes. 


\section{Acknowledgements}

The authors are particularly grateful to Petrucci Alessia for English translation and Marchitto Lino, Maisano Carla Maria and Marchitto Federica for organizational aspects.

\section{Conflicts of Interest}

The authors declare no conflicts of interest regarding the publication of this paper.

\section{References}

[1] Bellettiere, J., Healy, G.N., LaMonte, M.J., Kerr, J., Evenson, K.R., Rillamas-Sun, E., Di, C., Buchner, D.M., Hovell, M.F. and LaCroix, A.Z. (2018) Sedentary Behavior and Prevalent Diabetes in 6,166 Older Women: The Objective Physical Activity and Cardiovascular Health Study. The Journals of Gerontology: Series A. https://doi.org/10.1093/gerona/gly101

[2] Khandoker, A.H., Al-Angari, H.M., Khalaf, K., Lee, S., Almahmeed, W., Al Safar, H.S. and Jelinek, H.F. (2017) Association of Diabetes Related Complications with Heart Rate Variability among a Diabetic Population in the UAE. PLoS ONE, 12, e0168584. https://doi.org/10.1371/journal.pone.0168584

[3] Liu, W., Yang, X. and Huang, J. (2018) Efficacy and Safety of Insulin Degludec versus Insulin Glargine: A Systematic Review and Meta-Analysis of Fifteen Clinical Trials. International Journal of Endocrinology, 2018, Article ID: 8726046.

[4] Conde, C.A., Villa, M.M., Nino, C.A., Mojica, E. and Acevedo, J. (2016) Heart Rate Variability Parameters and the PNNX Family as Discriminators between Athletes and Sedentary People. Journal of Physical Education and Sport (JPES), 16, 1316-1325.

[5] Shields, A. and Sankaranarayanan, S. (2016) Basal Insulin Regime Change from Lantus to Toujeo Resulted in Fewer Hypoglycaemic Episodes in a 28-Year-Old Man with Diabetes Mellitus. BMJ Case Reports, 2016.

https://doi.org/10.1136/bcr-2016-215831

[6] Scheen, A.J. (2016) [INSULIN GLARGINE $300 \mathrm{U} / \mathrm{mL}$ (TOUJEO ${ }^{\circledR}$ )]. Revue médicale de Liège, 71, 101-107. (In French) 